\title{
A Rare Case of Malignant Lymphoma Occurred at Spinal Epidural Space: A Case Report
}

\author{
Hyun-Jun Cho, Jang-Bo Lee, Junseok W. Hur, Sung-Won Jin, Tai-Hyoung Cho, Jung-Yul Park \\ Department of Neurosurgery, Korea University Anam Hospital, University College of Medicine, Seoul, Korea
}

The sacral spinal epidural space is an uncommon site for primary malignant lymphomas, presenting with symptoms associated with cauda equina compression. Especially, lumbo-sacral epidural lymphoma has been reported to be very rare. We present a rare case of 29-year-old male with sacral spinal epidural malignant lymphoma. The patient complained of tingling sensation in his buttocks that was radiating to his calf. The neurological examination was normal. Magnetic resonance imaging (MRI) with contrast showed a well-defined extradural mass lesion at the mid L5 to mid S2 level. The lesion was iso- to hypointense on T1 and T2 weighted images and showed homogenous enhancement and a focal enhancement in the L5 vertebral body on post-contrast images. The patient underwent a L5-S2 laminectomy and subtotal excision of the lesion. Intra-operatively, the lesion was extradural and not densely adherent to the dura; the lesion was friable, not firm, fleshy, brownish and hypervascular. The histologic diagnosis was grade 2 non-Hodgkin's follicular lymphoma. Even though the primary spinal epidural non-Hodgkin's lymphoma is a very rare disease, clinicians should take it into consideration in the differential diagnosis of patients with spinal epidural tumor.

Key Words: Lymphoma • Epidural space lymphoma $\cdot$ Sacral lymphoma $\cdot$ Non-Hodgkin

\section{INTRODUCTION}

Non-Hodgkin's lymphoma is known to involve the central nervous system either primarily or by secondary spread, which tends to occur as part of widespread dissemination late in the disease ${ }^{9}$. Spinal cord compression is reported in up to $10.2 \%$ of non-Hodgkin's lymphoma patients, who often have an aggressive form of the disease ${ }^{7,9,11,15,16}$. It is reported that malignant lymphoma limited to the spinal epidural space is an uncommon initial presentation and participates up to $3.3 \%$ of all lymphomas and $9 \%$ of epidural spinal tumors ${ }^{17}$.

The sacral spinal epidural space is an uncommon site for primary malignant lymphomas, presenting with symptoms associated with cauda equina compression ${ }^{12)}$. These lesions are most common in middle-aged males ${ }^{12}$. The mid-thoracic spine is the most common site of involvement followed by the lum-

- Received: May 6, 2015 - Revised: June 15, 2015

- Accepted: June 16, 2015

Corresponding Author: Jang-Bo Lee, MD, PhD

Department of Neurosurgery, Anam Hospital, Korea University College

of Medicine, 73 Inchon-ro, Seongbuk-gu, Seoul 02841, Korea

Tel: +82-2-920-5729, Fax: +82-2-929-0629

E-mail: jblee42@gmail.com

@This is an Open Access article distributed under the terms of the Creative

Commons Attribution Non-Commercial License (http://creativecommons.org/ licenses/by-nc/3.0/) which permits unrestricted non-commercial use, distribution, and reproduction in any medium, provided the original work is properly cited. bar spine and the cervical spine ${ }^{12)}$. Especially, lumbo-sacral epidural lymphoma has been reported to be very rare.

We present a rare case of 29-year-old male with sacral spinal epidural malignant lymphoma, which on initial clinical and radiological examination was suggestive of an epidural tumor.

\section{CASE REPORT}

A 29-year-old, immunocompetent male was admitted with a 7-day history of pain in the left lower limb. He complained of tingling sensation in his buttocks that was radiating to his calf. He described the pain as aching in nature and radiating from the buttocks to the calf. The pain was aggravated by lying in the left lateral position, walking, and bending forward but was relieved by lying in the right lateral position.

The neurological examination was normal. Sensory examination did not reveal any abnormalities. Gait was antalgic with weight bearing on the right lower limb. Straight leg raise showed restriction at 40 degrees on the left side.

Magnetic resonance imaging (MRI) with contrast showed a well-defined extradural mass lesion that was $5.7 \times 2.1 \times 1.8 \mathrm{~cm}$ in size at the mid L5 to mid S2 level (Fig. 1, 2, 3). The lesion was iso- to hypointense on T1 and T2 weighted images and showed homogenous enhancement and a focal enhancement in the L 5 vertebral body on post-contrast images. The preoperative diagnosis was epidural tumor. 


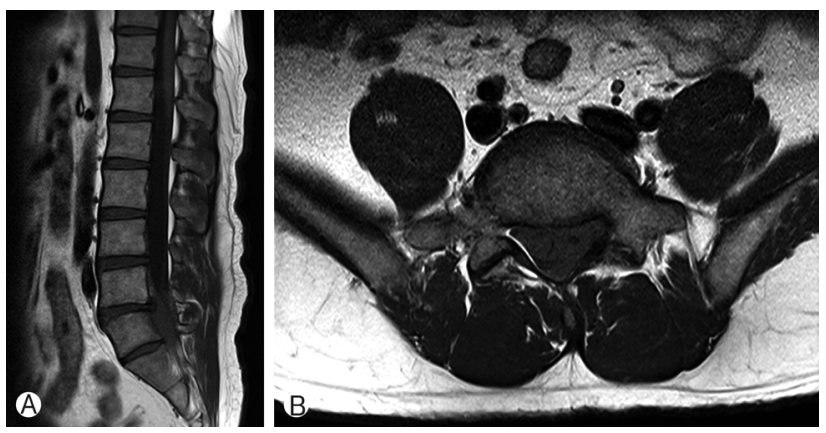

Fig. 1. Sagittal (A) and axial (B) images of $\mathrm{Tl}$-weighted magnetic resonance image showed homogenous iso-signal intense mass at the mid portion of $L 5$ and sacrum $(S 1,2)$.

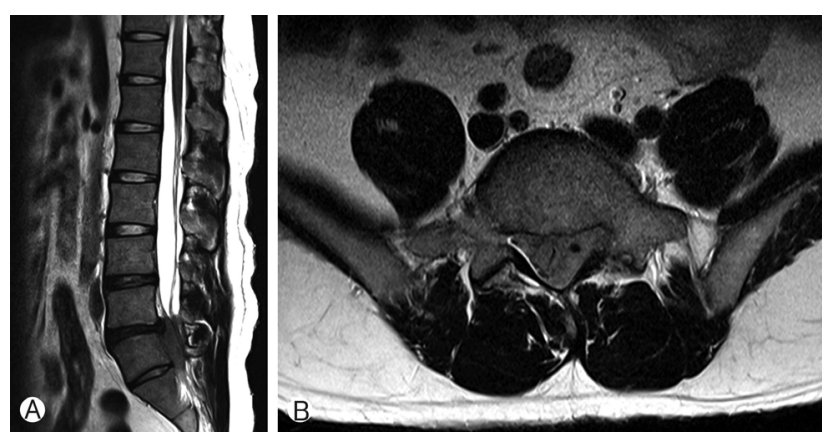

Fig. 2. Sagittal (A) and axial (B) images of T2-weighted magnetic resonance image were homogenously hypointense.

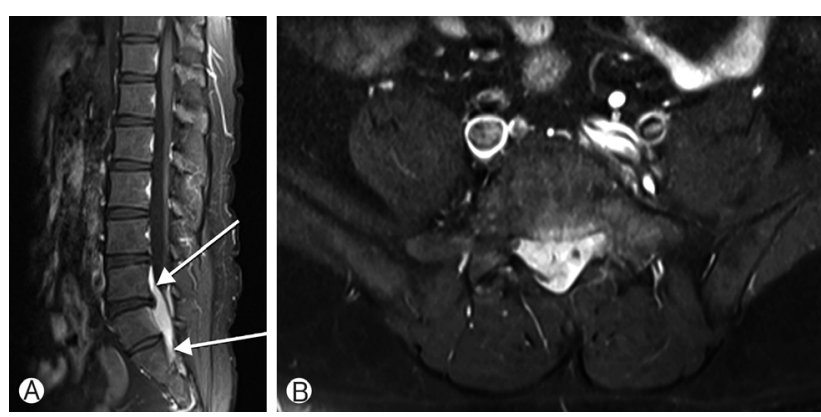

Fig. 3. Sagittal (A) and axial (B) images of post contrast magnetic resonance image showed an epidural spinal tumor, which was $5.7 \times 2.1 \times 1.8 \mathrm{~cm}$ in size at the mid L5 to mid S2 level and homogenously well-enhanced (arrow). It was compressing cauda equina, which might occurs the symptom of the patient.

The patient underwent a L5-S2 laminectomy and subtotal excision of the lesion. Intra-operatively, the lesion was extradural and not densely adherent to the dura; the lesion was friable, not firm, fleshy, brownish and hypervascular.

On histopathologic examination, the mass was described as an ill-defined, infiltrative lesion composed of heavy lymphoid infiltration with variable-sized lymphoid follicle for-
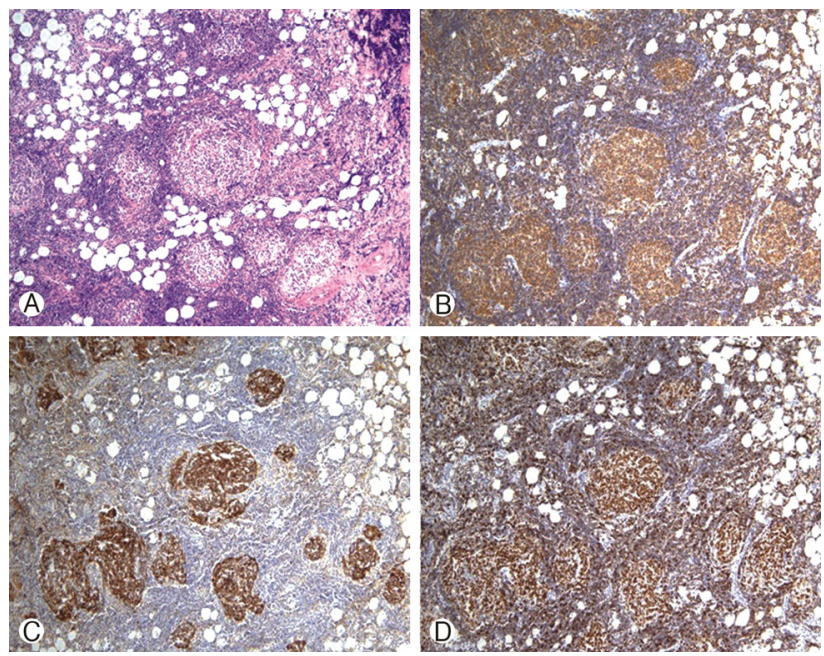

Fig. 4. (A) The lymphoid follicles and lymphoid cells infiltrate epidura I fat tissue. (B) The cells were positive for CD2O B cell marker. (C) The follicles contained CD21-positive follicular dendritic cells. (D) The follicles were positive for bcl-2. Then the histologic diagnosis was non-Hodgkin's follicular lymphoma.

mations (Fig. 4A). On immunohistochemical staining, the follicles and interfollicular cells were positive for CD20 (Fig. 4B). The follicular dendritic cells were CD21 positive, and the follicles were positive for bcl-2 (Fig. 4C, D). Ki-67 labeling was $30-40 \%$ in the follicular areas. The histologic diagnosis was grade 2 non-Hodgkin's follicular lymphoma.

The patient's radicular pain, tingling and numbness improved immediately following the surgery. Subsequently, the patient was worked up for systemic disease with MRI of the brain and positron emission tomography computed tomography, both of which were normal. Bone marrow examination was confirmed as a malignant lymphoma.

He received 6 cycles of chemotherapy with rituximab, cyclophosphamide, doxorubicin, vincristine and prednisolone (R-CHOP) regimen. After that, the lymphoma was confirmed as complete remission. He will receive further maintenance chemotherapy with rituximab.

\section{DISCUSSION}

Non-Hodgkin's lymphoma is an uncommon disease involving the spinal epidural space ${ }^{3)}$. Only $9 \%$ of spinal epidural tumors are lymphomas, with the thoracic spine (69\%) being the most common site followed by the lumbar (27\%) and cervical spine $(4 \%)^{17}$. Another study reported that only $4 \%$ of spinal epidural lymphoma was developed at lumbo-sacral area ${ }^{14)}$. Follicular lymphoma is the second most common type of lymphoma in the United States and Europe, accounting for app- 
roximately $20 \%$ of all Non-Hodgkin's lymphoma; however, this type of lymphoma is reported to be relatively rare in $\mathrm{Korea}^{10)}$.

Although follicular lymphoma is a lymph node-based lymphoma, it commonly disseminates to the extranodal sites. However, follicular lymphoma which occurs at extranodal sites as a primary lesion is uncommon ${ }^{4,58)}$. It is reported to be 0.8 $2.8 \%$ which forms epidural tumor primarily among malignant lymphomas ${ }^{6}$. Only one patient has been presented with a primary spinal epidural follicular lymphoma ${ }^{2}$. He was a 70year-old patient with localized disease to the thoracic spinal cord. The patient underwent surgery, chemotherapy and radiotherapy. There was no evidence of relapse after 4 months of follow up evaluation ${ }^{2)}$.

A slight male predominance is known for follicular lymphomas; a male-to-female ratio of $1.6: 1^{12}$. Our patient presented here was younger than the average patient with follicular lymphoma. Histologically, follicular lymphoma was considered because of the positivity of bcl-2 in follicles in contrast to the bcl-2 negativity in reactive follicles.

Several studies reported that the MRI findings reveal an iso/hypointense lesion on both T1/T2 weighted images and homogenous enhancement on post contrast images extending over multiple vertebrae ${ }^{12,13}$. The patient in this case report had a similar lesion on MRI.

On the aspect of management of spinal epidural lymphoma, several studies suggest that patients with features of spinal cord or cauda equina compression require to be treated with surgery for the purpose of both tissue diagnosis and decompression ${ }^{12)}$. Aabo et al, have reported no difference in outcome between patients undergoing decompressive laminectomy and radiotherapy vs. those receiving spinal radiation only ${ }^{1)}$. Patients with primary epidural non-Hodgkin's lymphoma who presented paraplegia of recent onset and underwent decompressive laminectomy showed significant neurological improvement. Meanwhile, surgery alone is reported not to be effective at patients' median overall survival ${ }^{6}$. The researchers thus suggest that the combination therapy of surgical and non-surgical treatment such as radiotherapy and/or chemotherapy should be done ${ }^{6}$. Here, we have performed an L5-S2 decompressive laminectomy with subtotal lesion excision with significant neurological improvement. Chemotherapy was followed with $\mathrm{R}-\mathrm{CHOP}$ regimen, which led the patient as complete remission of the disease.

The prognosis of primary spinal extradural non-Hodgkin's lymphoma with aggressive histological types is known to be poor in patients $>50$ years of age ${ }^{12}$. However, in young patients, long-term survival is favorable when they underwent surgical decompression followed by chemotherapy and radiotherapy. The overall mean survival period of patients is 8-9 months with less than $10 \%$ surviving one year ${ }^{16}$.

\section{CONCLUSION}

Even though the primary spinal epidural non-Hodgkin's lymphoma is a very rare disease which occur at only $9 \%$ of the epidural spinal tumor, clinicians should take it into consideration in the differential diagnosis of patients presenting with back pain secondary to spinal cord or cauda equina compression. We hereby report a rare case of the primary spinal epidural non-Hodgkin's lymphoma occurred at the sacral level.

\section{ACKNOWLEDGEMENT}

The manuscript submitted contain information about medical devices but there are no benefits in any form have been or will be received from a commercial party related directly or indirectly to the subject of this manuscript. The authors declare that they have no competing interests.

\section{REFERENCES}

1. Aabo K, Walbom-Jorgensen S: Central nervous system complications by malignant lymphomas: radiation schedule and treatment results. Int J Radiat Oncol Biol Phys 12:197-202, 1986

2. Alameda F, Pedro C, Besses C, Galito E, Marinoso ML, Munne A, et al: Primary epidural lymphoma. Case report. J Neurosurg 98:215-217, 2003

3. Barnard M, Perez-Ordonez B, Rowed DW, Ang LC: Primary spinal epidural mantle cell lymphoma: case report. Neurosurgery 47:1239-1241, 2000

4. Beltran BE, Quinones P, Morales D, Alva JC, Miranda RN, Lu G, et al: Follicular lymphoma with leukemic phase at diagnosis: a series of seven cases and review of the literature. Leuk Res 37:1116-1119, 2013

5. Chim CS, Loong F, Leung AY, Tsang J, Ooi GC: Primary follicular lymphoma of the small intestine. Leuk Lymphoma 45: 1463-1466, 2004

6. Cho JH, Cho DC, Sung JK, Kim KT: Primary malignant lymphoma in a spinal cord presenting as an epidural mass with myelopathy: a case report. Korean J Spine 9:265-268, 2012

7. Epelbaum R, Haim N, Ben-Shahar M, Ben-Arie Y, Feinsod M, Cohen Y: Non-Hodgkin's lymphoma presenting with spinal epidural involvement. Cancer 58:2120-2124, 1986

8. Fernandez de Larrea C, Martinez-Pozo A, Mercadal S, Garcia A, Gutierrez-Garcia G, Valera A, et al: Initial features and outcome of cutaneous and non-cutaneous primary extranodal follicular lymphoma. Br J Haematol 153:334-340, 2011

9. Friedman M, Kim TH, Panahon AM: Spinal cord compression in malignant lymphoma. Treatment and results. Cancer 37:14851491, 1976

10. Kim JM, Ko YH, Lee SS, Huh J, Kang CS, Kim CW, et al: WHO Classification of Malignant Lymphomas in Korea: Report 
of the Third Nationwide Study. Korean J Pathol 45:254-260, 2011

11. Levitt LJ, Dawson DM, Rosenthal DS, Moloney WC: CNS involvement in the non-Hodgkin's lymphomas. Cancer 45:545552, 1980

12. Mally R, Sharma M, Khan S, Velho V: Primary lumbo-sacral spinal epidural non-Hodgkin's lymphoma: A case report and review of literature. Asian Spine J 5:192-195, 2011

13. Mascalchi M, Torselli P, Falaschi F, Dal Pozzo G: MRI of spinal epidural lymphoma. Neuroradiology 37:303-307, 1995

14. Monnard V, Sun A, Epelbaum R, Poortmans P, Miller RC, Verschueren T, et al: Primary spinal epidural lymphoma: patients' profile, outcome, and prognostic factors: a multicenter Rare Cancer Network study. Int J Radiat Oncol Biol Phys 65:817823, 2006

15. Mullins GM, Flynn JP, el-Mahdi AM, McQueen JD, Owens AH Jr.: Malignant lymphoma of the spinal epidural space. Ann Intern Med 74:416-423, 1971

16. Perry JR, Deodhare SS, Bilbao JM, Murray D, Muller P: The significance of spinal cord compression as the initial manifestation of lymphoma. Neurosurgery 32:157-162, 1993

17. Salvati M, Cervoni L, Artico M, Raco A, Ciappetta P, Delfini R: Primary spinal epidural non-Hodgkin's lymphomas: a clinical study. Surg Neurol 46:339-343, 1996 